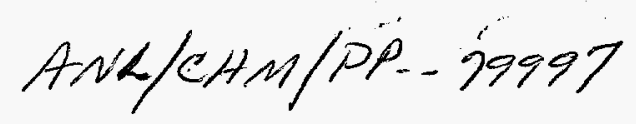

\title{
ELECTROSTATIC BASIS FOR MOLECULAR RECOGNITION IN PHOTOSYNTHESIS
}

David M. Tiede and Annie-Claude Vashista

Chemistry Division, Argonne National Laboratory

Marilyn R. Gunner

Department of Physics, City College of New York

An electrostatic basis for molecular recognition in photosynthesis has been found. Calculations with the crystal structure of the Rhodobacter sphaeroids photosynthetic reaction center, and experimental measurement of bimolecular electron transfer rates between the reaction center and a variety of water-soluble c-cytochromes, revealed that calculated patterns of electrostatic potential on bimolecular collision surfaces for each of the proteins can explain the reactivity of different reaction center-cytochrome pairs. This work by David Tiede and Annie-Claude Vashista from the Chemistry Division, Argonne National Laboratory, and Marilyn Gunner, from the Department of Physics, City College of New York, is significant because it provides a physical explanation for molecular recognition in the first steps of photosynthesis. It is also a starting point for examination of the role for electrostatics in the incorporation of membrane proteins into crystals and other ordered arrays that have potential for molecular device applications. This work was supported by the Department of Energy, Office of Basic Energy Sciences, Division of Chemical Sciences.

\section{DISCLAIMER}

\footnotetext{
This report was prepared as an account of work sponsored by an agency of the United States Government. Neither the United States Government nor any agency thereof, nor any of their employees, makes any warranty, express or implied, or assumes any legal liability or responsibility for the accuracy, completeness, or usefulness of any information, apparatus, product, or process disclosed, or represents that its use would not infringe privately owned rights. Reference herein to any specific commercial product, process, or service by trade name, trademark, manufacturer, or otherwise does not necessarily constitute or imply its endorsement, recommendation, or favoring by the United States Government or any agency thereof. The views and opinions of authors expressed herein do not necessarily state or reflect those of the United States Government or any agency thereof.
} 


\section{DISCLAIMER}

Portions of this document may be illegible in electronic image products. Images are produced from the best available original document. 


\title{
ELECTROSTATIC BASIS FOR MOLECULAR RECOGNITION IN PHOTOSYNTHESIS: \\ Electron-Transfer Kinetics and Electrostatic Properties of the Rhodobacter sphaeroides Reaction Center and Soluble c-Cytochromes
}

David M. Tiede and Annie-Claude Vashista Chemistry Division, Argonne National Laboratory

\author{
Marilyn R. Gunner \\ Department of Physics, City College of New York
}

An electrostatic basis for molecular recognition in photosynthesis has been found, based upon calculations from the crystal structure of the Rhodobacter sphaeroides photosynthetic reaction center, and supported by experimental measurements of water-soluble c-cytochrome "docking" on the reaction center. Besides providing a physical explanation for molecular recognition in photosynthesis, this work is significant because it is a starting point for the examination of the role for electrostatics in the incorporation of membrane proteins into crystals and other ordered arrays that have potential for molecular device applications.

Solar energy conversion in photosynthesis requires that reactive, bimolecular electrontransfer complexes are formed between the reaction center, the protein that carries out the initial conversion of solar energy to chemical energy, and specific secondary electron donors and acceptors. The molecular basis for recognition between the reaction center and its photosynthetic partners is determined by the charge and chemical properties of the associated proteins. This work identified a likely electrostatic mechanism for assembly of electron transfer complexes between the reaction center from $R b$. sphaeroides and a series of structurally homologous water-soluble c-cytochromes by identifying correlations between 
electron transfer and electrostatic properties of the reaction center and the various ccytochromes.

The kinetics of electron transfer between the reaction center and nine soluble ccytochromes were analyzed and compared to the patterns of the surface electrostatic potentials for each of the proteins. Characteristic first-order electron transfer rates for $1: 1$ complexes formed at low ionic strength between the reaction center and the different ccytochromes were identified, and found to vary by a factor of almost 100 , whereas secondorder rates were found to differ by greater than $10^{6}$. A correlation was found between the location of likely electrostatic interaction domains on each cytochrome and its characteristic rate of electron transfer. The interaction domains were identified by mapping electrostatic potentials, calculated from the Poisson-Boltzmann equation, onto simulated "encounter surfaces" for each of the cytochromes and the reaction center. For the reaction center, the ccytochrome binding domain was found to have almost exclusively net negative potential $(<-3$ kT) and to be shifted slightly towards the M-subunit side of the reaction center. The location of interaction domains of complementary, positive potential (>3 kT) differed for each cytochrome. The correspondence between electrostatic, structural and kinetic properties of 1:1 reaction center-cytochrome complexes lead to a proposed mechanism for formation of reaction center-cytochrome electron transfer complexes that is primarily driven by the juxtaposition of regions of delocalized complementary potential. In this mechanism the clustering of charged residues is of primary importance and not the location of specific residues. A consequence of this mechanism is that many different sets of charge distributions are predicted to be capable of stabilizing a specific configuration for a reaction centercytochrome complex. This mechanism for reaction center association with water-soluble ccytochromes fits molecular recognition mechanisms proposed for c-cytochromes in nonphotosynthetic systems. 
The success of this qualitative treatment in explaining cytochrome oxidation by the reaction center suggests that this electrostatic analysis may be expanded to investigate the role for protein electrostatics in the crystallization of membrane proteins and for the incorporation of proteins into ordered arrays relevant to molecular device applications.

\section{Acknowledgement}

The work at Argonne National Laboratory was supported by the Office of Basic Energy Sciences, Division of Chemical Sciences, U. S. Department of Energy. 


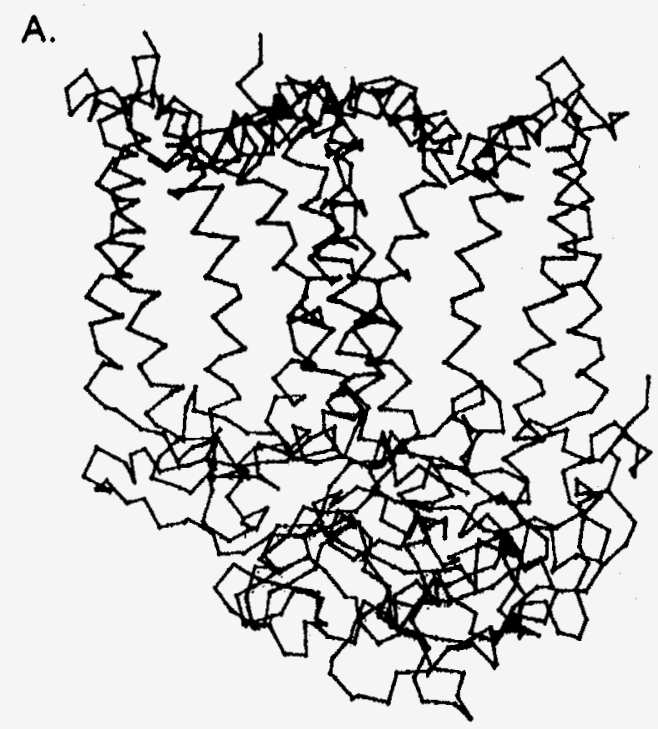

B.
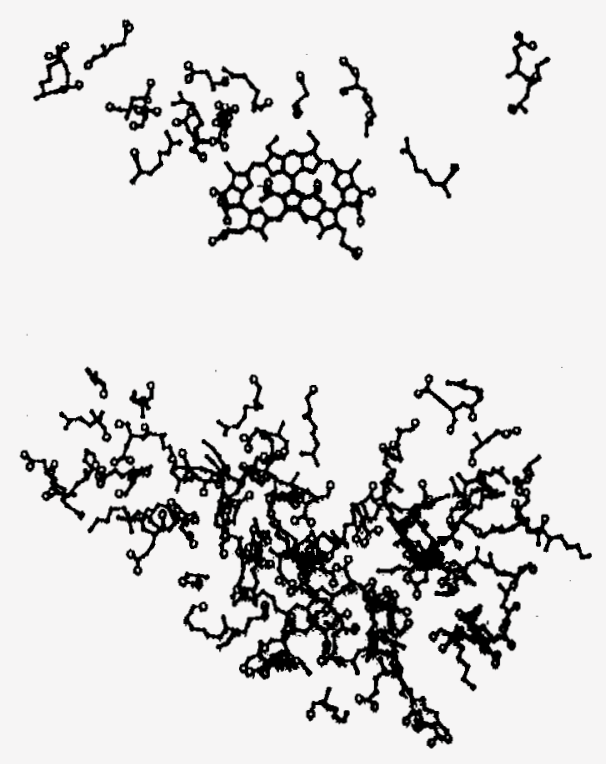

c.

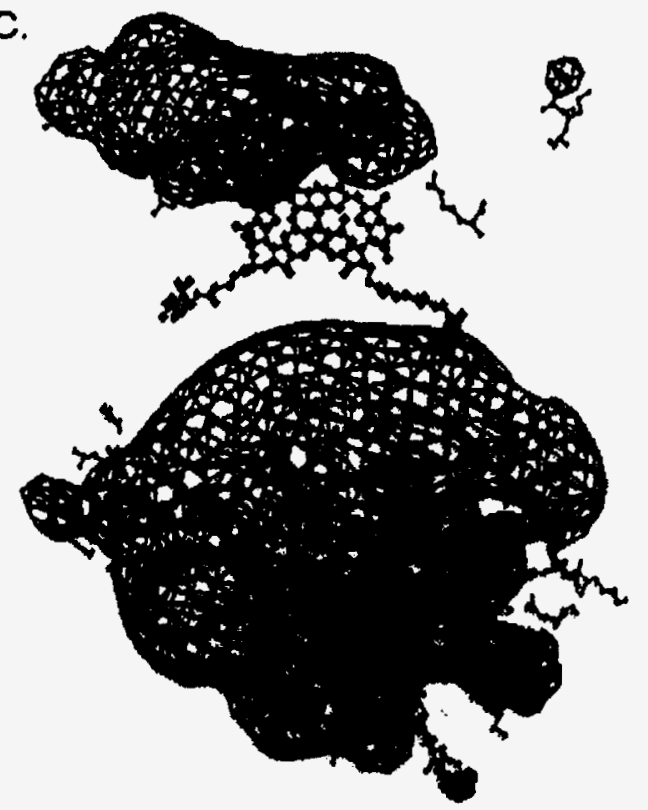

Figure 1. Part A shows the protein back-bone for the $R b$. sphaeroides reaction center. Part $B$ shows the location of ionizable amino acid side chains, and the bacteriochlorophyll dimer. The clustering of ionizable residues on the two opposite sides of the reaction center shows that these are the water-exposed domains, and the portion in the middle is solvated in the interior, non-aqueous lipid phase of the membrane. Part $\mathrm{C}$ shows an electrostatic isopotential surface calculated from the reaction center structure.

Fiqure 2 (attached). Electrostatic potentials mapped onto an bimolecular collision surface, or surface of closest approach, for the reaction center. This map is significant since it provides a clearer picture of locations on the reaction center that are likely to be important for electrostatic interactions in molecular recognition between the reaction center and companion eneroy and electron transfer partners. 


\section{ELECTROSTATIC POTENTIAL MAP ON A BIMOLECULAR COLLISION SURFACE - SURFACE OF CLOSEST APPROACH}

$$
\text { Red } \leq-3 k T \text { e --.-- Blue } \geq 3 \text { kT/e }
$$

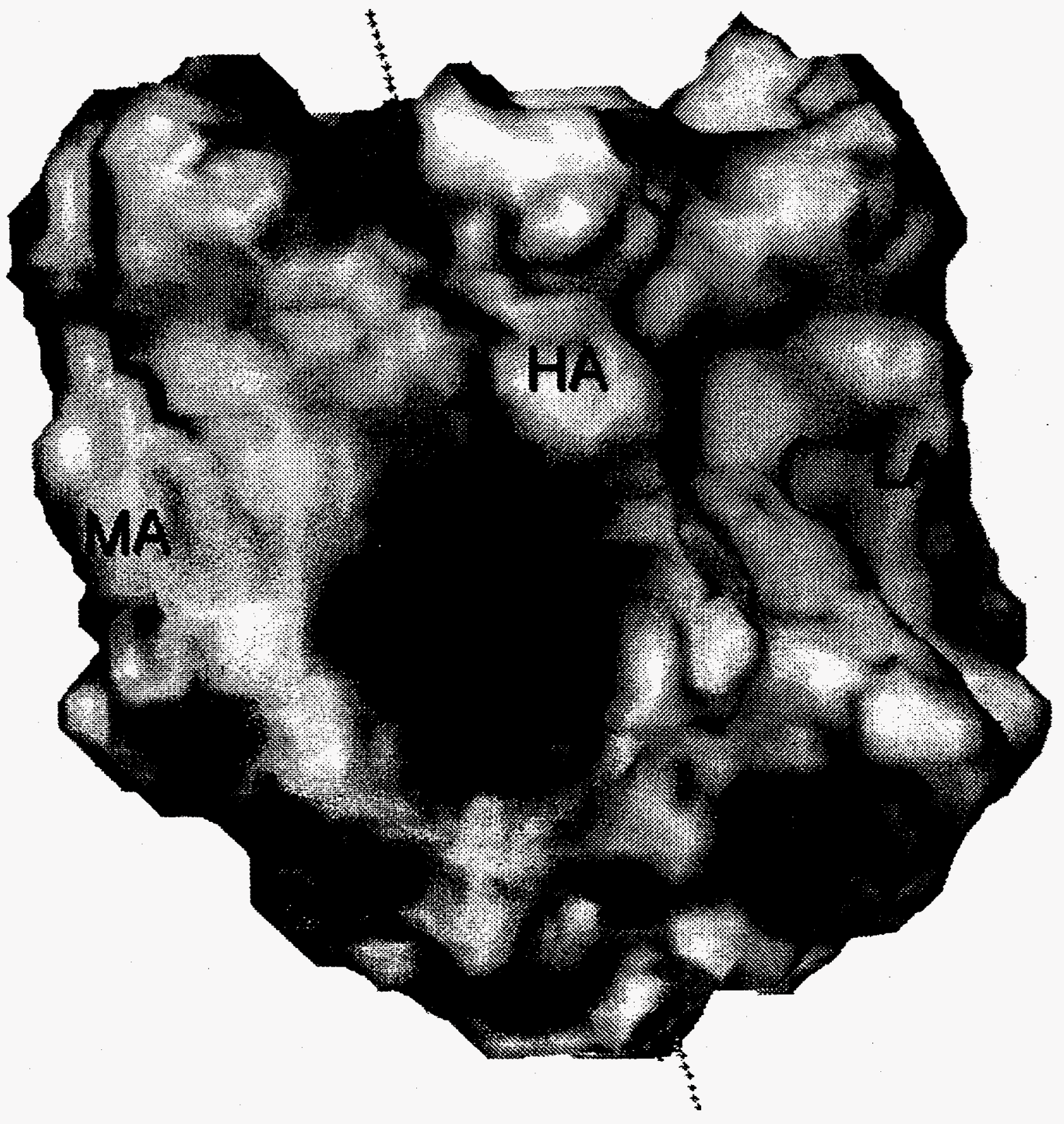

$1 \mathrm{kT} / \mathrm{e} \approx 25.6 \mathrm{meV} \approx 205 \mathrm{~cm}^{-1} \approx 0.59 \mathrm{kcal} / \mathrm{mole}$ 